\title{
O ENFOQUE DA ACESSIBILIDADE NO PLANEJAMENTO DA LOCALIZAÇÃO E DIMENSÃO DE SERVIÇOS DE SAÚDE*
}

\author{
Carmen Vieira de Sousa Unglert**
}

UNGLERT, C. V. de S. O enfoque da acessibilidade no planejamento da localização e dimensão de serviços de saúde. Rev. Saúde públ., S. Paulo, 24:445-52, 1990.

RESUMO: A localização geográfica e dimensão dos serviços de saúde são fatores que interferem em sua acessibilidade. Esta, por sua vez, é um pré-requisito fundamental para se garantír o acesso da população à saúde. Assim, foi realizado trabalho que se baseia na aplicação de uma metodologia que considera as relaçōes de variáveis geográficas, demográficas e sociais, em nível de cada realidade, possibilitando o estabelecimento de propostas alternativas para a localização e dimensão de serviços de saúde. Tal metodologia foi aplicada à Regiảo de Santo Amaro, Município de Sảo Paulo, Brasil. A contribuiçăo dada pela abordagem geográfica, demográfica e social de cada realidade abre ampla perspectiva quanto ao estudo de novos objetos, pela utilização da mesma metodologia cuja aplicação é recomendada à implementação de sistemas locais de saúde.

DESCRITORES: Acesso aos serviços de saúde. Planejamento de instituições de saúde. Necessidades e demanda de serviços de saúde.

\section{INTRODUÇÃO}

Um grande desafio com que se depara o planejamento do setor saúde é aquele que envolve a tomada de decisão sobre a localização e dimensão dos serviços. Se é fato que a tomada de decisão se faz quase sempre exclusivamente em nível político, quando se incursiona nas técnicas de planejamento propostas, acaba-se defrontando com modelos teóricos que nem sempre podem se apresentar como adequados a distintas realidades locais. Há propostas de modelos de áreas de influência de serviços de saúde baseados $\mathrm{cm}$ formas gcométricas definidas, como o sugerido por Onorkerhoraye ${ }^{7}$ para a Nigéria, onde os centros de saúde da comunidade deveriam servir a uma população de 10.000 a 20.000 habitantes, distribuídos em áreas geográficas justapostas, de forma pentagonal. Achabal-e Schoeman ${ }^{1}$ sugeriram árcas geográficas de influência com formato hexagonal, na implantação de um sistema para o atendimento universal à emergência, no setor saúde.

Há, também, modelos baseados $\mathrm{em}$ equações matemáticas, como os sugeridos por Sawyer ${ }^{10}$ e por Cromley e Schannon ${ }^{2}$, onde a alocação dos recursos é proposta a partir de modelos matemáticos de concentração urbana.

Do aprofundamento da análise para aplicação desses modelos, contudo, surgem questð̃es de fundamental importância, como a heterogeneidade tanto da distribuição geográfica da população quanto de características dessa mesma população, o que acaba por conduzir o planejador a se deter na análise de conceitos fundamentais, de eqüidade e de acessibilidade para a realidade concreta que é objeto de seu estudo.

Eqüidade é aqui entendida como a igualdade no acesso à saúde e deve ser provida como um direito de todo o cidadão. O acesso à saúde envolve aspectos que extrapolam a assistência à saúde. Neles atuam fatores sócio-econômicos e culturais que interagem com aspectos intersetoriais ligados à própria estrutura política de cada país. Não se pode, todavia, deixar de enfatizar, como faz Gibbard ${ }^{4}$, que a acessibilidade dos serviços de saúde é um fator de fundamental importância para que essa eqüidade seja concretizada. Essa acessibilidade deve ser garantida do ponto de vista: geográfico, através do adequado planejamento da localização dos serviços de saúde; econômico, pela remoção de barreiras derivadas do sistema de pagamento ou contribuição pelo usuário; cultural, com a adequação das normas e técnicas dos serviços aos hábitos e costumes da população em que se insercm; e funcional, através de oferta de serviços oportunos e adequados às necessidades da população8,9.

\footnotetext{
- Parte da tese de doutorado da autora, sob o título "Contribuição para o estudo da localização de serviços de saúde: uma abordagem de geografia em saúde pública", apresentada à Faculdade de Saúde Pública da Universidade de São Paulo, em 1986.

* Departamento de Saúde Materno-Infantil da Faculdade de Saúde Pública da Universidade de São Paulo - Av. Dr. Arnaldo, 715 - 01255 - São Paulo, SP - Brasil.
} 
A cidade de São Paulo apresenta enorme complexidade para os que se propoem a garantir essa acessibilidade à população, no setor saúde. Com seus mais de 11 milhôes de habitantes, distribuídos de forma irregular, a cidade possui áreas plenamente urbanizadas, que contam com toda infra- estrutura, e outras, com características rurais, que, em grande parte, não dispõem de serviços de saúde e, por vêzes, nem mesmo de meios de transporte coletivo. O planejamento da localização de serviços, nessa realidade, deve respeitar as características de cada área, considerando suas peculiaridades, e qualquer modelo teórico que não leve em conta esses fatores possivelmente estará fadado ao insucesso.

A proposta aqui apresentada é baseada numa metodologia que considera que a cidade não deve ser planejada a partir de modelos que a subdividam, mas sim que o planejamento se efetue partindo da realidade específica de cada local e do confronto entre seus problemas e recursos de saúde.

\section{MATERIAL E MÉTODO}

A área geográfica estudada compreende o Subdistrito de Paz de Santo Amaro, o Subdistrito de Paz de Capela do Socorro e o Distrito de Paz de Parelheiros, situados na Região sul do Município de São Paulo (Fig. 1). O levantamento de dados populacionais baseou-se no censo de 1980 da Fundação Instituto Brasileiro de Geografia e Estatística ${ }^{3}$. Estabeleceu-se uma projeção populacional até 1984, utilizando-se taxas de crescimento populacional para microrregiőes propostas pela Secretaria do Planejamento da Prefeitura do Município de São Paulo*, bem como dados referentes ao crescimento de favelas naquela região, da Secretaria do Bem Estar Social da Prefeitura do $\mathrm{Mu}$ nicípio de São Paulo, no período de 1980 a 1984.

A metodologia utilizada para a subdivisão da região foi aquela proposta em trabalho anterior (Unglert ${ }^{12}$ ), para a caracterização de áreas, baseada em critérios geográficos, demográficos e sociais, que propõe uma subdivisão da região inicial em 31 áreas de estudo (Fig. 2), com limites geográficos e composição demográfica definidos. Dessa forma, o estudo da distribuição da população e de suas necessidades com relação a consultas médicas, bem como da distribuição dos recursos existentes e das necessidades de extensão da rede de serviços de saúde foi estabelecido considerando-se as 31 áreas de estudo anteriormente propostas.

Com referência aos recursos de saúde, foram objeto de estudo os serviços básicos de saúde existentes na região, pertencentes à rede pública municipal, estadual e federal que prestam atendimento do tipo ambulatorial. Efetuou-se o levanta-

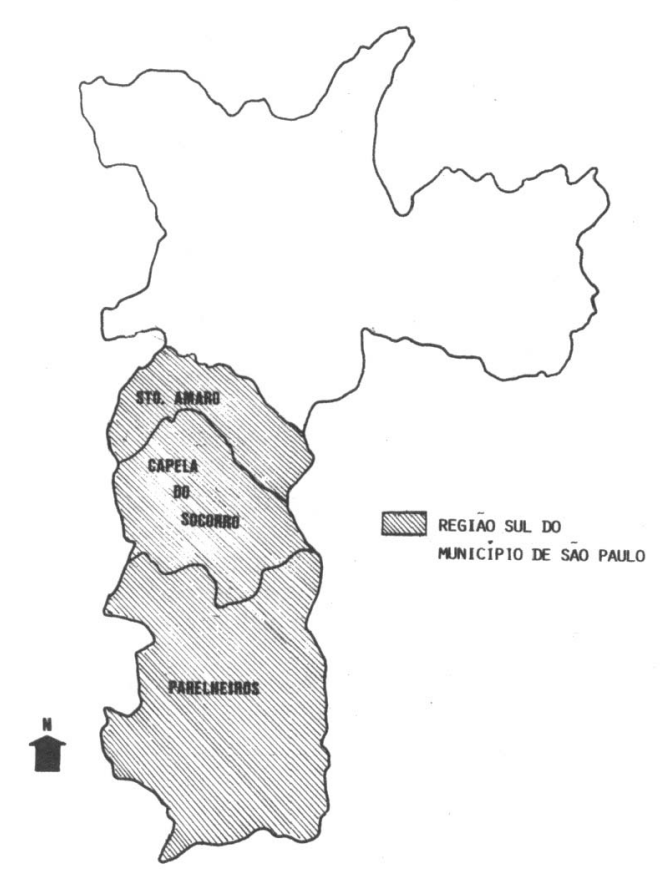

Fig. 1 - Localização geográfica da Região Sul do Município de São Paulo.

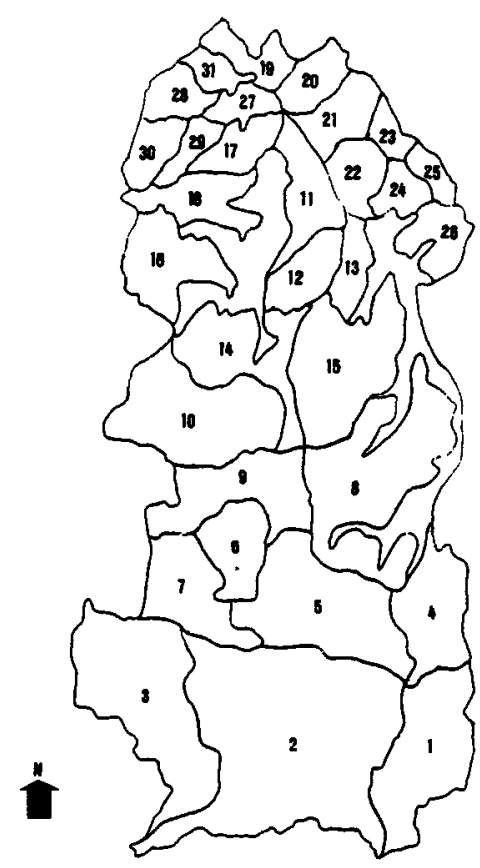

Fig. 2 - Distribuição geográfica das 31 áreas de estudo. Região Sul do Estado de São Paulo. 
mento de unidades, sua localização, número de consultórios médicos e de médicos existentes por unidade e por ano, nos anos de 1980 e 1984.

Optou-se por utilizar o instrumento consulta médica como unidade de comparação entre as necessidades de serviços de saúde e a capacidade de atendimento dos recursos disponíveis, adotandose, para tanto, alguns parâmetros e estabelecendose alguns conceitos.

Com relação à estimativa das necessidades de consulta médica, por parte da população, optou-se pelo parâmetro do Instituto Nacional de Assistência e Previdência Social, que é de 2 consultas/ habitante/ano. Acrescentou-se a esse valor as consultas de controle de saúde de diferentes grupos populacionais, de acordo com as normas em vigor, no período em estudo, da Secretaria de Saúde do Estado de São Paulo, quais sejam, 4,5 e 3 consultas médicas de controle de saúde por ano, respectivamente, para os grupos de gestantes, menores de 1 ano e crianças de 12 a 24 meses.

A estimativa da capacidade de atendimento dos serviços de saúde baseou-se nos parâmetros de 5 consultas/médico/hora, jornada de trabalho de 4 horas/dias e 220 dias/ano trabalhados. Os parâmetros utilizados para elaboração de proposta de localização e dimensão de serviços de saúde foram: extensão geográfica, densidade demográfica e taxa de crescimento de cada área, analisados juntamente com as necessidades e recursos de saúde de cada área de estudo.

\section{RESULTADOS E DISCUSSÃO}

A Tabela 1 mostra a extensão das áreas de estudo e a densidade demográfica das mesmas nos anos de 1980 e 1984 . Tanto em relação à extensão como ao número de habitantes as áreas são bastante heterogêneas. Deve-se frisar, contudo, que a intenção da metodologia aplicada não é a de estabelecer áreas geográfica ou demograficamente homogêneas, como foi exposto anteriormente. Dessa forma, as áreas de número 1 a 10 têm características rurais, enquanto que outras abrigam um número de habitantes muito maior. Por outro lado, a taxa de crescimento populacional específica de cada área também foi muito variada. As áreas 11 e 22 foram as que apresentaram os maiores percentuais de crescimento anual, com uma taxa da ordem de $16 \%$ ao ano, enquanto que áreas como as de números 13, 15 e 18 chegaram a apresentar um crescimento populacional negativo.

Deve-se salientar que quase toda a região é protegida por legislação específica de proteção aos mananciais, devido à presença de represas de água que servem como fonte de abastecimento de água da população do Município de São Paulo e de outros municípios da Grande São Paulo. Uma das medidas tomadas pelas autoridades é a de se criar obstáculos ao crescimento da densidade demográfica da região através de lei de zoneamento, com legislação voltada para o uso do solo. Apesar das medidas vigentes, pode-se constatar que a densidade demográfica da região continua crescendo e de forma perigosa, pois se não se trata de crescimento previsto em lei, é grande a possibilidade de que se trate de loteamentos clandestinos e subabitações, o que acaba por agravar a situação, por não contarem com infra-estrutura de saneamento adequado.

O levantamento dos serviços de saúde existentes na região compreendeu 44 unidades de saúde, sendo duas pertencentes ao INAMPS, 19 à

TABELA 1

Extensão e densidade demográfica das áreas de estudo, Região de Santo Amaro, São Paulo, nos anos de 1980 e 1984

\begin{tabular}{|c|c|c|c|}
\hline \multirow[t]{2}{*}{ Área } & \multirow[t]{2}{*}{$\mathrm{Km}^{2}$} & \multicolumn{2}{|c|}{ Densidade demográfica (hab $\left./ \mathrm{km}^{2}\right)$} \\
\hline & & 1980 & 1984 \\
\hline 1 & 31,4 & 3,0 & 3,1 \\
\hline 2 & 90,9 & 10,2 & 10,4 \\
\hline$\overline{3}$ & 47,5 & 17,7 & 18,1 \\
\hline 4 & 20,0 & 31,3 & 32,2 \\
\hline 5 & 38,2 & 59,3 & 61,0 \\
\hline 6 & 13,8 & 160,5 & 165,1 \\
\hline 7 & 19,9 & 137,9 & 141,8 \\
\hline 8 & 45,4 & 54,3 & 55,9 \\
\hline 9 & 23,7 & 361,4 & 371,7 \\
\hline 10 & 35,9 & 187,1 & 192,5 \\
\hline 11 & 12,1 & $5.109,7$ & $9.662,8$ \\
\hline 12 & 9,7 & $7.699,3$ & $7.854,0$ \\
\hline 13 & 7,2 & $9.210,8$ & $7.700,9$ \\
\hline 14 & 23,5 & $1.142,9$ & $1.174,7$ \\
\hline 15 & 32,9 & $2.387,8$ & $2.026,1$ \\
\hline 16 & 19,0 & $1.126,1$ & $1.171,9$ \\
\hline 17 & 8,6 & $8.528,3$ & $8.752,2$ \\
\hline 18 & 13,2 & $3.766,9$ & $3.624,3$ \\
\hline 19 & 7,2 & $4.632,6$ & $6.949,0$ \\
\hline 20 & 8,0 & $9.430,3$ & $9.545,9$ \\
\hline 21 & 10,2 & $6.439,5$ & $9.791,0$ \\
\hline 22 & 9,4 & $7.325,3$ & $13.379,9$ \\
\hline 23 & 4,1 & $16.313,0$ & $19.856,4$ \\
\hline 24 & 6,2 & $12.480,8$ & $15.247,1$ \\
\hline 25 & 4,0 & $19.121,4$ & 19267,8 \\
\hline 26 & 8,3 & $4.410,4$ & $5.176,6$ \\
\hline 27 & 5,5 & $9.509,3$ & 9.8163 \\
\hline 28 & 7,8 & $6.880,6$ & $7.094,1$ \\
\hline 29 & 5,6 & $10.767,6$ & $11.226,5$ \\
\hline 30 & 7,8 & $6.025,2$ & $6.213,7$ \\
\hline 31 & 5,7 & $9.150,6$ & $9.512,4$ \\
\hline Total & 582,7 & $2.137,6$ & $2.469,0$ \\
\hline
\end{tabular}

Fonte: Empresa Metropolitana de Planejamento da Grande São Paulo, Fundação $\operatorname{IBGE}^{3}$ (1980). 


\section{TABELA 2}

Distribuição do número de consultórios médicos e de médicos existentes, segundo áreas de estudo,

Região de Santo Amaro, São Paulo, nos anos de 1980 e 1984

\begin{tabular}{|c|c|c|}
\hline \multirow[t]{2}{*}{ Årea } & 1980 & 1984 \\
\hline & Consultórios Médicos & Consultórios Médicos \\
\hline
\end{tabular}

\begin{tabular}{|c|c|c|c|c|}
\hline 1 & - & - & - & - \\
\hline 2 & 二 & 二 & - & $\bar{z}$ \\
\hline 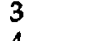 & - & - & - & $\bar{z}$ \\
\hline 5 & - & - & - & - \\
\hline 6 & - & - & - & - \\
\hline 7 & - & - & - & - \\
\hline 8 & - & - & 2 & 2 \\
\hline 9 & 3 & 2 & 3 & 3 \\
\hline 10 & $\overline{7}$ & $\overline{5}$ & $\overline{7}$ & $\overline{8}$ \\
\hline 12 & 12 & 20 & 20 & 44 \\
\hline 13 & - & - & - & - \\
\hline 14 & - & $\overline{5}$ & $\overline{13}$ & $\overline{31}$ \\
\hline $\begin{array}{l}15 \\
16\end{array}$ & 工 & - & 10 & - \\
\hline 17 & 10 & 10 & 12 & 22 \\
\hline 18 & 2 & 3 & 7 & 9 \\
\hline 19 & - & - & 8 & 5 \\
\hline 20 & 15 & 14 & 14 & 23 \\
\hline 21 & 10 & 36 & 16 & 83 \\
\hline 22 & 1 & 1 & 1 & 5 \\
\hline 23 & - & - & 9 & 7 \\
\hline 24 & 9 & 5 & 9 & 11 \\
\hline 25 & - & - & 4 & 7 \\
\hline 26 & - & - & 6 & 7 \\
\hline 27 & 4 & 4 & 5 & 9 \\
\hline 28 & 9 & 8 & 17 & 25 \\
\hline & - & - & 3 & 6 \\
\hline & 3 & 3 & 14 & 18 \\
\hline 31 & 5 & 4 & 10 & $\Pi$ \\
\hline Total & 94 & 120 & 180 & 326 \\
\hline
\end{tabular}

Prefeitura do Município de São Paulo, e 23 à Secretaria do Estado da Saúde. Algumas áreas permanecem sem nenhuma unidade de saúde, no ano de 1984, enquanto que outras acham-se contempladas som até quatro unidades.

O levantamento efetuado do número de consultórios médicos e de médicos, por área, em 1980 e 1984, é apresentado na Tabela 2. Como se pode observar, o número de consultórios, foi duplicado no período em estudo, e de 14 áreas que possuíam consultórios em 1980, passou-se a ter 20 áreas contando zom esse recurso, em 1984.

Com relação ao número de médicos, observou-se que o mesmo quase triplicou no período estudado, ;endo que o maior aumento ocorreu na área 21. Esse tumento, contudo, foi generalizado atingindo praicamente todas as áreas que já contavam com esses rrofissionais, além da expansão que ocorreu com a rresença de médicos em seis novas áreas.
A Tabela 3 mostra que apesar de na análise da distribuição de recursos ter chamado a atenção a carência dos mesmos, nas áreas rurais (de 1 a 10) a necessidade de consultas nessas áreas é relativamente pequena. A área 22 é a que apresenta maior necessidade global de consultas, seguida da área 11.

Efetuou-se o estudo da capacidade instalada operacional, ou seja, do número de consultas médicas, por área de estudo, possíveis de serem oferecidas com a utilização máxima, segundo os critérios adotados, dos médicos consultantes existentes nas unidades. Na Tabela 4, verifica-se que a área 21 é a que apresenta o maior potencial de atendimento, seguida das áreas 12,28 e 20. Confrontando-se os dados de 1980 e 1984 observa-se uma tendência à desconcentração, visto a área 20 , por exemplo, ter reduzido, em termos percentuais, sua participação de um valor de $11,7 \%$, em 1980 , para $7,1 \%$, em 1984; as áreas 21 e 12, também apresentaram uma redução relativa, sugerindo que os investimentos, no período em estudo, ocorreram de forma a promover uma desconcentração dos mesmos, procurando atingir novas áreas ou aquelas que contava com um menor número de profissionais. A capacidade instalada operacional da região quase que duplicou no período em estudo.

A capacidade instalada real estudada refere-se ao número de consultas médicas, por área de estudo, possíveis de serem oferecidas com a utilização máxima, segundo os critérios adotados, dos consultórios médicos existentes nas unidades. $\mathrm{Na}$ Tabela 4 pode-se observar que a área 12 é a que apresenta o maior potencial de atendimentos, seguida pelas áreas 28 e 30 . Por outro lado, as áreas $10,13,14$ e 16, além das de números 1 a 7 permaneceram em 1984 sem equipamento instalado, apresentam potencial de atendimento nulo. Observou-se também, que a capacidade instalada real da região praticamente duplicou no período em estudo, não só pela presença de novas unidades, como também pelo crescimento físico daquelas já existentes.

Comparando-se a capacidade instalada real com a operacional verifica-se que mesmo que toda a capacidade operacional fosse utilizada ela só atingiria $54,3 \%$ da capacidade instalada real, ou seja, haveria ainda $45,7 \%$ de ociosidade dos consultórios. Verifica-se, portanto, que se poderia duplicar o número de consultas médicas oferecidas à população, apenas com o preenchimento das vagas existentes nas diferentes unidades que já se encontravam instaladas na região.

Comparando-se ainda os dados de capacidade instalada operacional e real com os de necessidades de consulta médica, verifica-se que, em 1980, o potencial de consultas médicas oferecido pelos médicos existentes na região cobria apenas $16,0 \%$ das necessidades e a capacidade instalada real atingia $41,8 \%$ das necessidades, no mesmo 
TABELA 3

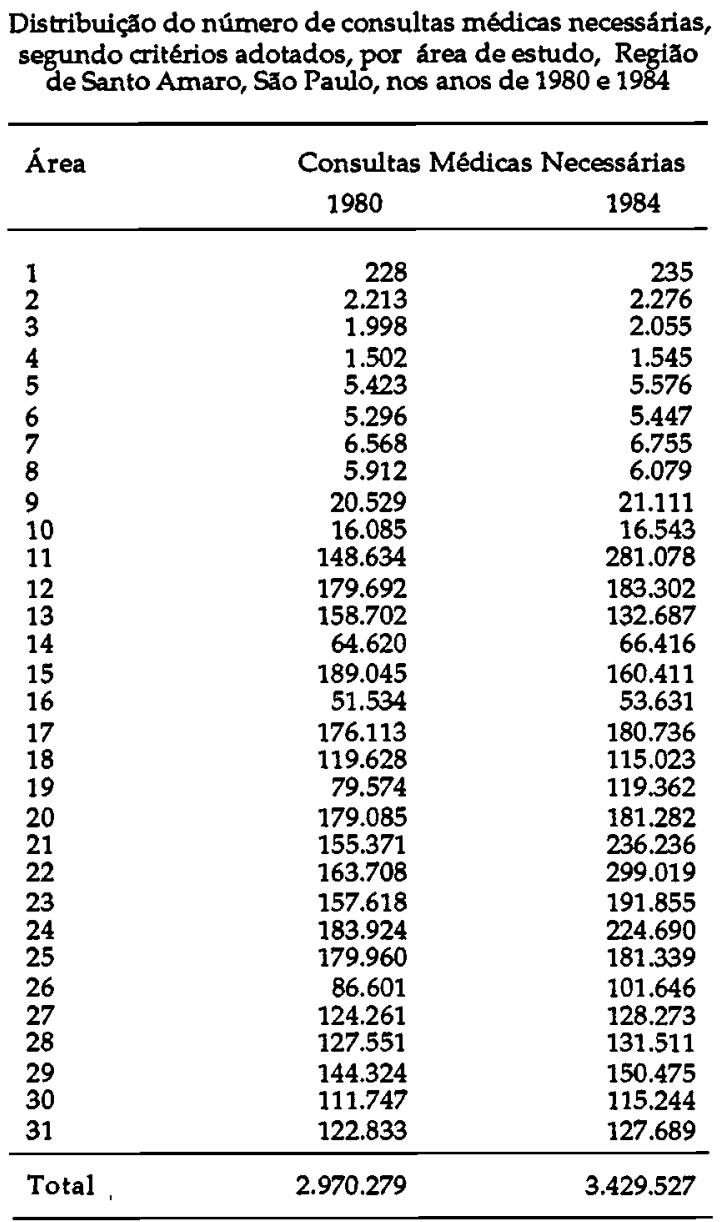

ano. Em 1984, a capacidade instalada operacional conseguiu satisfazer $37,6 \%$ das necessidades da região, sendo que a capacidade instalada real, nesse ano, chegou a atingir $69,3 \%$ das necessidades. Observa-se, dessa forma, que a maior deficiência se concentra nos recursos humanos estudados, o que sugere que um investimento nesse setor possibilitaria 0 atendimento de mais de dois terços das necessidades.

A Tabela 5 mostra a distribuição, nos anos de 1980 e 1984, do número complementar de médicos e de consultórios necessários, por área de estudo e por ano. Verifica-se que houve uma redução do número de consultórios necessários, no período, observandose que nem sempre o investimento ocorreu em áreas de maior prioridade. As que em 1980 apresentavam maior deficiência eram as de número $25,13,22$ e 23. Em 1984 verifica-se que as áreas com maior necessidade são as $22,11,13$ e 25 , sendo que as $8,9,12,15$, $20,28,30$ e 31 apresentavam um excedente mínimo de consultórios e que nas áreas 12,28 e 30 esse excedente é maior, correspondendo esse fato a um investimento aplicado em áreas não prioritárias. Obser-

\section{TABELA 4}

Distribuição do número de consultas por área de estudo com a utilização máxima da capacidade instalada operacional e real, Regiảo de Santo Amaro. Såo Paulo, nos anos de 1980 e 1984

\begin{tabular}{|c|c|c|c|c|}
\hline \multirow[t]{2}{*}{ Ârea } & \multicolumn{2}{|l|}{1980} & \multicolumn{2}{|c|}{1984} \\
\hline & Operacional & 1 Real & Operacional & Real \\
\hline 1 & - & 一 & - & - \\
\hline 2 & - & - & - & - \\
\hline 3 & - & 一 & 一 & - \\
\hline 4 & - & - & - & - \\
\hline 5 & - & - & - & - \\
\hline 6 & - & - & - & - \\
\hline 7 & - & - & - & - \\
\hline 8 & - & - & 7.920 & 26.400 \\
\hline 9 & $\begin{array}{r}7.920 \\
-\end{array}$ & 39.600 & 11.800 & 39.600 \\
\hline $\begin{array}{l}10 \\
11\end{array}$ & $19 . \overline{800}$ & $92 . \overline{400}$ & $31 . \overline{680}$ & $92 . \overline{00}$ \\
\hline 12 & 79.200 & $\begin{array}{r}92.400 \\
158.400\end{array}$ & $\begin{array}{r}31.080 \\
174.240\end{array}$ & 264.000 \\
\hline 13 & - & - & - & - \\
\hline 14 & - & - & - & - \\
\hline 15 & 19.800 & 52.800 & 83.160 & 171.600 \\
\hline 16 & - & - & - & - \\
\hline $\begin{array}{l}17 \\
18\end{array}$ & $\begin{array}{l}39.600 \\
11.880\end{array}$ & $\begin{array}{r}132.000 \\
26.400\end{array}$ & $\begin{array}{l}87.120 \\
35.640\end{array}$ & $\begin{array}{r}158.400 \\
92.400\end{array}$ \\
\hline 19 & - & - & 19.800 & 105.600 \\
\hline 20 & 55.440 & 198.000 & 91.080 & 184.800 \\
\hline $\begin{array}{l}21 \\
22 \\
23\end{array}$ & $\begin{array}{r}142.560 \\
3.960 \\
-\end{array}$ & $\begin{array}{r}132.000 \\
13.200 \\
\end{array}$ & $\begin{array}{r}328.680 \\
19.800 \\
27.720\end{array}$ & $\begin{array}{r}211.200 \\
13.200 \\
118.800\end{array}$ \\
\hline $\begin{array}{l}24 \\
25\end{array}$ & $\begin{array}{r}19.800 \\
-\end{array}$ & $\begin{array}{r}118.800 \\
-\end{array}$ & $\begin{array}{l}43.560 \\
27.720\end{array}$ & $\begin{array}{r}118.800 \\
52.800\end{array}$ \\
\hline 26 & 一 & - & 27.720 & 79.200 \\
\hline 27 & 15.840 & 52.800 & 35.640 & 660.000 \\
\hline $\begin{array}{l}28 \\
29\end{array}$ & $\begin{array}{r}31.680 \\
-\end{array}$ & 118.800 & $\begin{array}{l}99.000 \\
23.760\end{array}$ & $\begin{array}{r}224.400 \\
39.600\end{array}$ \\
\hline 30 & 11.880 & 39.600 & 71.280 & 164.800 \\
\hline 31 & 15.840 & 66.000 & 43.560 & 132.000 \\
\hline Total & 475.200 & .240 .800 & 1.290 .960 & 2.356 .000 \\
\hline
\end{tabular}

va-se ainda, que algumas áreas, com rápido crescimento de necessidades não foram beneficiadas com nenhum consultório no período em estudo, como é o caso das áreas 22 e 11 . Com referência ao número complementar de médicos necessários, observa-se que houve uma redução de 630 para 540 médicos, no período em estudo. Verifica-se, assim, que dos 206 novos profissionais que passaram a atuar na área, 116 foram utilizados para cobrir o aumento das necessidades, derivado do crescimento populacional. Em 1980 nenhuma das áreas apresentava excesso de profissionais. Em 1984, a situação ainda é de necessidade de recursos, com exceção das áreas 21 e 8, podendo-se presumir que os recursos foram distribuídos pelas diferentes áreas, sendo que algumas, como a 11 e a 22 foram muito pouco beneficiadas, o que agravou o problema da carência de profissionais nas mesmas, enquanto que nas demais a tendência foi de uma redução do número complementar de médicos necessários.

\section{ANÁLISE DE PROPOSTAS ALTERNATIVAS}

No presente trabalho procurou-se descrever por 
um lado a distribuição das necessidades da população, expressa em termos do número de consultas médicas necessárias $e$, por outro lado a distribuição de recursos, em termos do número de profissionais médicos e de consultórios médicos existentes. A partir daí e de acordo com critérios pré-estabelecidos, efetuou-se uma análise comparativa, chegando-se a uma previsão do número complementar de consultas necessárias, por área de estudo.

Procedeu-se, então, à análise de algumas propostas alternativas levando-se em conta, contudo, que a localização e dimensão das unidades, bem como a especificação de seus serviços, deve sempre ser definida através de um processo que garanta a participação permanente da comunidade e dos profissionais de saúde do nível local.

Defende-se, portanto, uma posição do planejador em Saúde Pública, em que caiba a esse profis-

\section{TABELA 5}

Distribuição do número complementar de consultórios médicos e médicos necessários, por área de estudo,

Região de Santo Amaro, São Paulo, nos anos de 1980 e 1984

\begin{tabular}{|c|c|c|c|}
\hline \multirow{2}{*}{ Área } & 1980 & \multicolumn{2}{|l|}{1984} \\
\hline & Consultórios Médicos & Consultórios & Médicos \\
\hline
\end{tabular}

\begin{tabular}{lrrrr}
1 & 0,0 & 0,1 & 0,0 & 0,1 \\
2 & 0,2 & 0,6 & 0,2 & 0,6 \\
3 & 0,2 & 0,5 & 0,2 & 0,5 \\
4 & 0,1 & 0,4 & 0,1 & 0,4 \\
5 & 0,4 & 1,4 & 0,4 & 1,4 \\
6 & 0,4 & 1,3 & 0,4 & 1,4 \\
7 & 0,5 & 1,7 & 0,5 & 1,7 \\
8 & 0,4 & 1,5 & $-1,5$ & $-0,5$ \\
9 & $-1,4$ & 3,2 & $-1,4$ & 2,3 \\
10 & 1,2 & 4,1 & 1,2 & 4,2 \\
11 & 4,3 & 32,5 & 14,3 & 63,0 \\
12 & 1,6 & 25,4 & $-6,1$ & 2,3 \\
13 & 12,0 & 40,1 & 10,1 & 33,5 \\
14 & 4,9 & 16,3 & 5,0 & 16,8 \\
15 & 10,3 & 42,7 & $-0,8$ & 19,5 \\
16 & 3,9 & 13,0 & 4,1 & 13,5 \\
17 & 3,3 & 34,5 & 1,7 & 23,6 \\
18 & 7,1 & 27,2 & 1,7 & 20,1 \\
19 & 6,0 & 20,1 & 1,0 & 25,1 \\
20 & $-1,4$ & 31,2 & $-0,3$ & 22,8 \\
21 & 1,8 & 3,2 & 1,9 & $-23,3$ \\
22 & 11,4 & 40,3 & 21,7 & 70,5 \\
23 & 11,9 & 39,8 & 5,5 & 41,4 \\
24 & 4,9 & 41,4 & 8,0 & 45,7 \\
25 & 13,6 & 45,4 & 9,7 & 38,8 \\
26 & 6,5 & 21,9 & 1,7 & 18,7 \\
27 & 5,4 & 27,3 & 4,7 & 23,4 \\
28 & 0,7 & 24,2 & $-7,0$ & 8,2 \\
29 & 10,9 & 36,4 & 8,4 & 32,0 \\
30 & 5,5 & 25,2 & $-5,3$ & 11,1 \\
31 & 4,3 & 27,0 & $-0,3$ & 21,2 \\
\hline Total & 130,9 & 629,9 & 79,8 & 540,0 \\
\hline & & & & \\
& & & &
\end{tabular}

sional a elaboração de uma proposta preliminar acessivel, quer aos elementos da área de decisão dos serviços, quer à população. Considera-se que a caracterização das necessidades, por área de estudo, agregada aos demais dados estudados, deve compor um conjunto de informaçoes e análises preliminares que auxiliarão na decisão final do processo. Mas essa decisão deverá, sempre, ser tomada com a ativa participação da população, que é quem vai usufruir desses novos serviços.

Cabe, aqui, referir Lebebvre ${ }^{6}$, quando afirma que "as ciências parcelares têm apenas um alcance programático e que se se admitir que os elementos por elas levantados abrangem uma totalidade, acaba-se por realizar um projeto que, na prática, traduz a ideologia dos tecnocratas". Gilmore igualmente salienta a importância da decisão ser primariamente social, referindo que a sociedade deve decidir sobre suas prioridades e sobre a alocação de recursos. Dessa forma, a análise de propostas que se fará a seguir tem o intento de demonstrar as possibilidades alternativas que sugerem os dadós analisados sem, contudo, exprimir uma proposta fechada quanto à localização e dimensionamento das unidades. Por essa razão não se considerou necessária a análise individualizada de cada uma das áreas, mas optou-se por discutir alternativas comuns a algumas áreas, passando-se, assim, a efetuar uma categorização das mesmas. Com base nessa categorização a decisão estaria em nível de se estabelecer uma concentração ou uma desconcentração das unidades de saúde através de sua localização e dimensão, face à análise do crescimento populacional, da densidade demográfica e da dimensão das diferentes áreas de estudo. No caso de áreas com características rurais como as de 1 a 10 , que apresentam baixas taxas de crescimento populacional, além de contar com áreas extensas, a carência de recursos é pequena em termos numéricos. Contudo, trata-se de áreas que, na sua maioria, não conta com nenhum recurso, apresentando-se totalmente a descoberto. A sugestão para tais áreas seria a da utilizaçăo de uma unidade desconcentrada, ou seja, no momento em que a necessidade não chega a atingir o mínimo de um consultório, a sugestão se faz no sentido de desconcentrar, fragmentando o atendimento de um mesmo profissional por diversas áreas.

Essa estratégia mostrou-se viável com a utilização de equipes volantes de saúde ${ }^{11}$, cujo planejamento e implantação se estabeleceram de forma conjunta entre a comunidade e técnicos da instituição.

Para áreas com maior densidade populacional o processo proposto é o mesmo, qual seja o da análise de uma proposta preliminar, através de um grupo misto de trabalho, com elementos da comunidade e da instituição. A proposta preliminar estaria baseada na concentração ou desconcentração de recursos face às características das diferentes áreas. 
Assim, áreas de alta densidade demográfica e crescimento populacional acelerado como, por exemplo, as de números $22,23,24,25$ e 29 sugerem que a melhor alternativa seja a da construção de novas unidades grandes, comportando cada uma delas, em média, cinco consultórios médicos. No caso da área 22, por exemplo, a sugestão seria a da construção de cinco unidades com cinco consultórios cada. De grande importância se reveste o fato de se propor, também, a complementação do quadro de pessoal das unidades já existentes nessas áreas.

Por outro lado, existem áreas como as de números $12,20,28,30$ e 31 que se mostram com recursos físicos suficientes não havendo, a curto prazo, necessidade de novas construçőes, mas apenas de complementação do quadro de médicos das unidades existentes. No caso das áreas 17,19 e 26, a alternativa de se construir uma nova unidade só deveria ser tomada após a verificação da impossibilidade de adaptação ou expansão das unidades existentes. Áreas como as 13 e 15, com crescimento populacional negativo, devem ser cobertas, contando-se com o fato de que provavelmente não terão, a médio prazo, necessidade de expansāo. No caso da área 13, a construção de duas novas unidades, com 5 consultórios cada, parece ser a melhor sugestão, face às características da área. No caso da área 15 haveria necessidade apenas de se complementar o quadro de pessoal das unidades existentes.

Áreas como as de números 14,16 e 18, que possuem dimensões relativamente grandes, comportam uma população bem mais rarefeita, que não atinge 5.000 habitantes $/ \mathrm{Km}^{2}$, e sua taxa de crescimento populacional anual é relativamente baixa. Como a área 16 não possui nenhuma unidade de saúde, a proposta a se sugerir para tal área seria a da construçẫo de duas unidades, contando cada uma com 3 consultórios. $\mathrm{Na}$ área 18, a deficiência não atinge 2 consultórios, sendo proposta uma unidade com 3 consultórios, além da complementação do pessoal das unidades existentes. No caso da área 14, a sugestão seria a da construção de duas unidades, com 3 consultórios cada.

A área 11 apresenta um crescimento populacional acelerado, dimensões intermediárias e necessidade de cerca de 15 consultórios. A proposta para essa área seria a da construção de 4 unidades, com 5 consultórios, pois face ao grande ritmo de crescimento populacional apresentado, os 5 consultórios excedentes propostos seriam necessários a médio prazo. Outras áreas, como a de número 27 , apresentam crescimento populacional relativamente baixo, densidade populacional intermediária e são de pequenas dimensões, razão pela qual se supõe que também comportariam unidades com 5 consultórios, já que a distância a ser percorrida pela população não seria longa.
A área 21 tem características peculiares. Trata-se de área de dimensão e densidade demográfica intermediárias e o crescimento populacional é acelerado, mas por se tratar de área central da região de Santo Amaro, apresenta um acúmulo de médicos, com um excedente de 23 profissionais. Tal excesso não se verifica em termos de consultórios. A sugestão para essa área seria a análise inicial da possibilidade de expansão das unidades existentes ou a construção de uma unidade, com 5 consultórios. Outra medida, também proposta, seria a do estudo do remanejamento dos médicos excedentés para outras áreas que apresentam carência desses profissionais.

Assim, através da utilização de uma mesma metodologia, chegou-se a propostas bastante diversificadas que acabaram por variar entre sugestôes como a da implantação de equipes volantes de saúde (que realmente foram implantadas $e$ estão funcionando até o presente ${ }^{11}$ ) e sugestões como a da construção de unidades maiores, com 5 consultórios médicos funcionando em três períodos, mostrando-se, assim, a proposta metodológica, adequada a distintas realidades.

$O$ presente trabalho teve por objetivo a demonstração da aplicabilidade de tal metodologia no campo do planejamento da localização e extensão de serviços de saúde. Contudo, vislumbra-se a perspectiva de utilizá-la no aprofundamento do conhecimento das distintas realidades, aplicando-a a outros objetos, quer seja em estudos sobre morbi-mortalidade, cujo interesse seria o conhecimento de coeficientes que expressassem realidades mais específicas, quer seja na instituição de áreas de abrangência de serviços de saúde, visando ao estabelecimento de áreas geográficas, demográficas e socialmente definidas, cujo sistema de controle de saúde ficaria a cargo de uma equipe de saúde, também definida.

O presente trabalho procurou contribuir, através da aplicação de uma nova metodologia, para a operacionalização de um sistema de saúde que reconheça e enfatize a importância do estabelecimento de sistemas locais de saúde, baseados não em modelos teóricos, mas cuja estrutura e funcionamento emanem da realidade de cada local.

\section{CONCLUSÕES}

1. O estudo da localização e dimensão de serviços de saúde torna-se mais efetivo se forem consideradas variáveis de natureza geográfica, demográfica e social.

2. A metodologia utilizada permite a identificação de necessidades de serviços de saúde e a elaboração de propostas com maior adequação à realidade local. 
3. A metodologia proposta possibilita o enfoque da acessibilidade no planejamento da localização e dimensão de serviços de saúde.

4. O presente trabalho demonstra a viabili- dade de aplicação da metodologia proposta.

5. A utilização da metodologia proposta mostra-se compatível com a concepção de sistemas locais de saúde.

UNGLERT, C. V. de S. [The importance of accessibility in the planning of localization and size of health services]. Rev. Saúde públ., S. Paulo, 24:445-52, 1990.

ABSTRACT: Geographical localization and size are two factors which play an important role in accessibility to health services. This accessibility, in its turn, is a basic requirement for ensuring the access of the population to health. A study was undertaken, in Santo Amaro, a suburb of the city of S. Paulo, Brazil, on the application of a methodology which takes into account the relationships among the geographical, demographic and social variables, in each particular situation, leading to the formulation of alternative proposals for the localization and size of health services. The kind of approach to each situation employed in this study proved fundamental in opening up a broad range of possibilities for the study of other subjects through the application of the same methodology, especially recommended for the implanting of local health systems. demand.

KEYWORDS: Health services accessibility. Health facility planning. Health services needs and

\section{REFERÊNCIAS BIBLIOGRÁFICAS}

1. ACHABAL, D. B. \& SCHOEMAN, M. E. F. An examination of altemative emergency ambulance systems: contributions from an economic geography perspective. Soc.Sci.Med., 13D: 81-6, 1979.

2. CROMLEY, E. K. \& SCHANNON, G. W. The establishment of health maintenance organizations: a geographical analysis. Amer. J. publ. Hlth, 73: 184-7, 1983.

3. FUNDAÇÃO IBGE. Censo demográfico; dados distritais: Säo Paulo. Rio de Janeiro, 1982. v. 1, t. 3, n. 17. ( $9^{\circ}$ Recenseamento Geral do Brasil, 1980).

4. GIBBARD, A. The prospective pareto principle and equity of access to health care. Milbank mem. Fd Quart., 60: 399-428, 1982.

5. GILMORE, A. Access to health care: how can costs be contained? Canad.med.Ass.J., 130: 614-8, 1984.

6. LEBEBVRE, H. O direito à cidade. São Paulo, Edit. Documentos, 1969.

7. ONOKERHORAYE, A. G. A suggested framework for the provision of health facilities in Nigeria. Soc.Sci.Med., 10: 565-70, 1976.

8. ORGANIZACION PANAMERICANA DE LA SALUD. Reunion especial de ministros de salud de las Ameri- cas. Washington, D.C., 1978. (Documentos Oficiales, 155).

9. ORGANIZACION PANAMERICANA DE LA SALUD. Extension de la cobertura de servicios de salud con las estrategias de atencion primaria y participacion de la cumunidad. Washington, D. C., 1978. (Documentos Oficiales, 156).

10. SAWYER, D. Assessing access constraints on system equity: source of care differences in the distribution of medical services. Hlth Serv.Res., 17: 27-44, 1982.

11. UNGLERT, C. V. de S. et al. Equipe volante de saúde uma altemativa para o atendimento da população $\mathrm{n}$ ral do Município de São Paulo. In: Congresso Paulista de Saúde Pública, 2\%/Congresso Nacional da ABRASCO, 10², São Paulo, 1983. ProgramaRegimento-Resumos. São Paulo, 1983. p. 117.

12. UNGLERT, C. V. de S. Contribuição para o estudo da localização de serviços de saúde: uma abordagem de geografia em saúde pública. São Paulo, 1986. [Tese de Doutoramento - Faculdade de Saúde Pública da USP].

Recebido para publicação em 16/2/1990. Aprovado para publicaçâo em 21/8/1990. 